\title{
Initial MST radar observations of upper tropospheric-lower stratospheric duct-like structures over Jicamarca, Peru
}

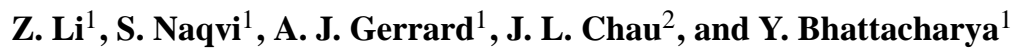 \\ ${ }^{1}$ Center for Solar-Terrestrial Research, New Jersey Institute of Technology, 323 Martin Luther King Jr. Boulevard, 101 \\ Tiernan Hall, Newark, NJ 07102-1982, USA \\ ${ }^{2}$ Radio Observatorio de Jicamarca, Instituto Geofisico del Peru, Lima, Peru
}

Correspondence to: A. J. Gerrard (gerrard@njit.edu)

Received: 11 March 2011 - Published in Atmos. Chem. Phys. Discuss.: 4 July 2011

Revised: 14 October 2012 - Accepted: 17 October 2012 - Published: 22 November 2012

\begin{abstract}
Persistent wind jet structures along zonal and meridional fields, believed to be caused by stationary gravity waves, were detected in February 1999 in mesospherestratosphere-troposphere (MST) radar wind measurements of the troposphere and lower stratosphere over Jicamarca, Peru. Over a continuous seven day span of MST-data analyzed in this study, two days of observations showed signatures of wave-like structures in the upper troposphere/lower stratosphere wind jets associated with the phases of the stationary gravity waves. We believe these wave-like structures are ducted gravity waves. We present these initial observations, their characteristics, and the results of simple numerical simulations used in an attempt to mimic these observed features. Although a fair replication of the observed ducted structure in the numerical model is found, the observed period of $\sim 90 \mathrm{~min}$ is nonetheless much longer than what is traditionally observed. As a result, the specific physical nature of the observed structures is not fully established. Nevertheless, given the high quality of the observations, we demonstrate here that continued analysis of this data set and concurrent modeling efforts will allow for a better understanding of Doppler ducts at high spatial and temporal resolution, and the results presented here can ultimately be applied to studies of middle atmospheric fronts, ducts, and bores.
\end{abstract}

\section{Introduction}

The observed behavior of mesospheric fronts, primarily in all-sky imagery utilizing mesospheric emissions of $\mathrm{O}, \mathrm{OH}$, and $\mathrm{Na}$, presents a challenge to our understanding of the dynamics of the mesosphere-lower thermosphere (MLT) re- gion. The first observation of a mesospheric frontal structure, i.e., a phenomenon characterized by an intense wave front followed by a series of trailing crests propagating in the MLT, was reported in Taylor et al. (1995). Based on these observations, and inspired by the similarity between such airglow disturbance events and undular tidal bores in rivers, Dewan and Picard (1998) and Dewan and Picard (2001) proposed a semi-quantitative model of such a phenomena and coined the term: "mesospheric bore". The physical basis of these structures is still a matter of investigation (Brown et al., 2004), and therefore we shall refer to such observations as "mesospheric fronts". Smith et al. (2003) reported the observation of a mesospheric front that traveled at the same altitude over $1200 \mathrm{~km}$ without significant dissipation - thus representing a unique process of mesoscale energy transport in the middle atmosphere. Snively and Pasko (2003), Snively et al. (2007), and Snively and Pasko (2008) showed that the appearance of a mesospheric front was much like the signature of a ducted gravity wave, albeit missing an intense leading band. Brown et al. (2004) showed that such mesospheric fronts are associated with passing tropospheric weather fronts, likely generating gravity waves propagating upwards, and were sustained by thermal ducts within mesospheric inversion layers (MILs) (Meriwether and Gerrard, 2004). This concept was supported by the observations of She et al. (2004) using concurrent measurements of winds and temperatures using $\mathrm{Na}$ lidar. Recently, Fechine et al. (2009) and Simkhada et al. (2009) reported the observations of a mesospheric front in a Doppler duct (Chimonas and Hines, 1986) during the 1 October 2005 SpreadFEx campaign in South America and over Hawaii, respectively. 

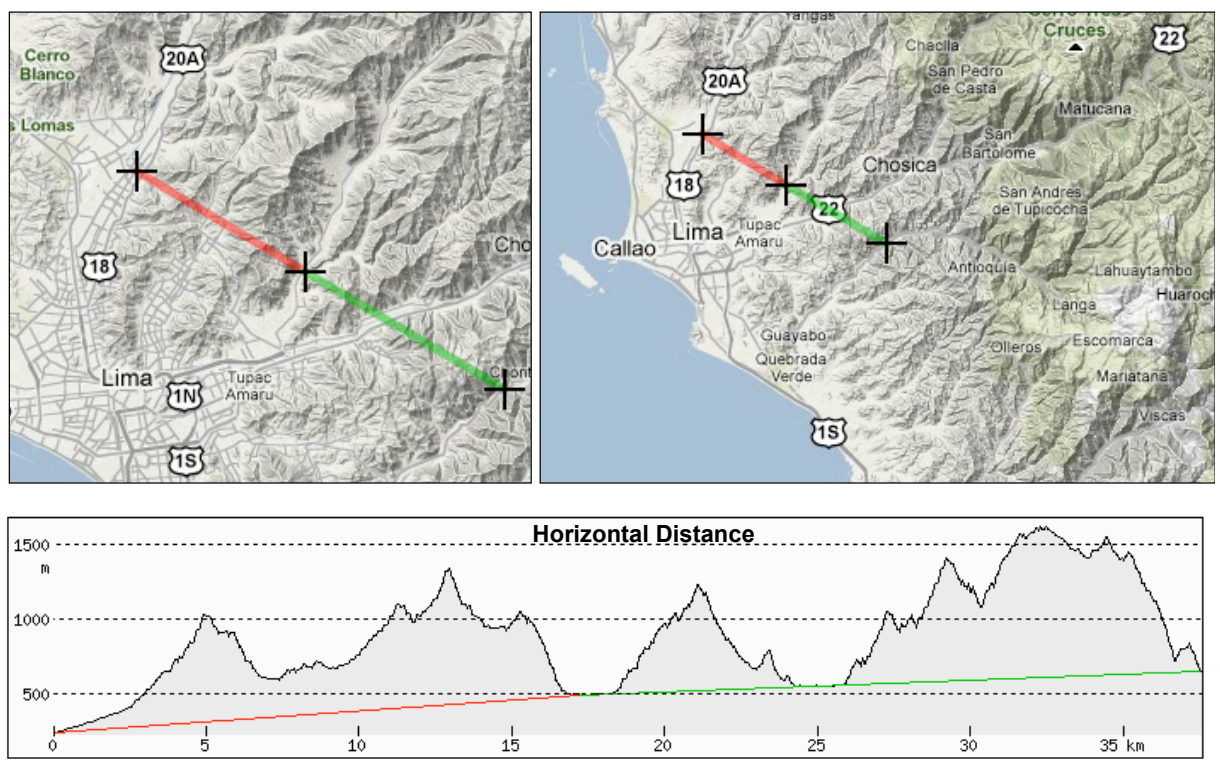

Fig. 1. Top panels show the location and topography surrounding the Jicamarca radar site in Peru, South America. The straight line passing from the northwest to the southeast cuts a height profile as shown in the lower panel, with red indicative of space to the northwest and green indicative of the southeast. The point where the red line and green line meet is the location of Jicamarca. North is towards the top of the page. (Maps from Google Earth, topology from HeyWhatsThat Path Profiler at www.heywhatsthat.com)

To date, there is considerable uncertainty in the realms of (a) what mechanisms sustain mesospheric fronts (the role of thermal ducts and Doppler ducts, occurring independently or together), (b) how a mesospheric front propagates (whether as bores (Dewan and Picard, 1998), as ducted gravity waves (Snively et al., 2007), or as something else entirely), (c) the potential impact of such phenomena on the MLT region in particular, and (d) mechanisms that lead to the creation of a mesospheric front. Progress in these areas is hampered by the fact that mesospheric fronts are very difficult to study due to the challenges associated with measuring the fundamental base-state parameters of the MLT region, let alone the acquisition of synoptic-state of the MLT. Even high-resolution modeling efforts are challenging due to the myriad of physics occurring over dramatically different spatial and temporal scales.

In an effort to better answer these questions, we have turned to high resolution upper tropospheric/lower stratospheric wind observations made with the mesospherestratosphere-troposphere (MST) radar over Jicamarca, Peru $\left(12^{\circ} \mathrm{S}, 77^{\circ} \mathrm{W}\right)$. Inspection of data from the February 1999 time-period shows consistently [temporally] steady, sustained winds in the zonal and meridional directions that spatially vary in the vertical. The structure of these winds is indicative of stationary gravity waves - likely the result of climatological southeasterly or northwesterly tropospheric flow over the terrain (as seen in Fig. 1). Thus, it was suspected that these stationary gravity wave wind fields would form a natural laboratory for the high resolution study of any Dopplerducted [and potentially thermally-ducted] gravity waves and bore-like phenomena, likely generated by non-stationary or quasi-stationary sources like tropical convection.

In this paper, an analysis of wave-like structures observed over Jicamarca - which resemble Doppler-ducted gravity waves - are presented. However, we show that the structures have a number of characteristics that differ from observations of Doppler-ducted gravity waves found in other investigations, opening up the possibility that the dynamical processes behind these observations may not originate in ducted waves. The unusual characteristics of the wave-like structure in the data prompted these attempts to numerically simulate the ducting of a traveling gravity wave and investigate whether the output of a relatively simple model results could be matched to observations.

\section{Observations}

Prior MST observations (e.g., Woodman and Guillen (1974)) using the Jicamarca incoherent scatter radar were presented and discussed in Riggin et al. (2002) and Riggin et al. (2004). The $50-\mathrm{MHz}$ radar is divided into four separate antennas pointing at a $2.5^{\circ}$ zenith angle in the cardinal directions. Coherent backscatter caused by irregularities in the atmospheric refractive index are collected by each antenna in the radial direction, and the first moment of each spectra is used to determine the radial Doppler shift. The raw data are then post-processed yielding reduced zonal and meridional wind data in $2 \mathrm{~min}$ temporal realizations and $150 \mathrm{~m}$ range bins. Range-time plots of data samples, taken on days 57 and 59 
of February 1999, are shown in Fig. 2 (left column). It is important to note that the signal-to-noise ratio varies with altitude due to shifts in the backscattered power; with the highest SNR values being measured in the $1-12 \mathrm{~km}$ and the $17-21 \mathrm{~km}$ regions. This does not imply that data outside of these regions are poor, but rather that they are relatively more noisy.

Also shown in Fig. 2 [right column] are the daily mean zonal and meridional winds for the two sample days presented here. A fifth-order polynomial was fitted to the daily mean vertical wind profile and then subtracted from each of the individual measurements - the residue being the wind perturbations. These wind perturbations were then low-pass filtered with filter cutoffs at $1 \mathrm{~h}$ and $1.5 \mathrm{~km}$ in the time and range domains, respectively, for display purposes only. The resultant low-pass filtered wind perturbations are also shown in Fig. 2 (center column).

Detailed analysis of 7 consecutive days of Jicamarca MST data from February 1999 shows four notable features. First, the winds were consistently steady over the course of multiple days at a time, with deviations being short-lived $(<1 \mathrm{~h})$ and comparatively weak $\left(<5 \mathrm{~m} \mathrm{~s}^{-1}\right)$ with respect to the daily mean profile. Over the course of 3-4 consecutive days, the westerly and easterly wind jets/bands slowly vary with altitude, but showed no coherent phase progression.

Second, vertical wind profiles of both the zonal and meridional winds across the upper troposphere and lower stratosphere indicate a steady background wind superposed with a sinusoidal variation; particularly above $10 \mathrm{~km}$. Removal of the daily mean wind showed perturbations (Figure 2, center column) that resemble stationary gravity wave structures (i.e., fixed phase structure in time). Assuming that these gravity waves are indeed stationary, the dispersion relationship for gravity waves can be used to infer their horizontal wavelength. On day 59, for instance, the dominantly zonal and easterly horizontal wind speed over the $15-23 \mathrm{~km}$ altitude is estimated to be $\sim 10 \mathrm{~m} \mathrm{~s}^{-1}$, with a vertical wavelength of $\sim 7 \mathrm{~km}$. Utilizing a climatological Brunt-Vaisala frequency, one can show that the horizontal wavelength is $\sim 8 \mathrm{~km}$. For day 57 , the zonal background wind is weaker than the mean, with an estimated value of $\sim 7 \mathrm{~m} \mathrm{~s}^{-1}$ and vertical wavelength is much smaller at an estimated $\sim 4 \mathrm{~km}$, thus yielding an estimated horizontal wavelength of $\sim 9 \mathrm{~km}$. If the horizontal wind profiles were constant with height, the horizontal wavelengths would approximately match the dominant spatial modulation of the ground terrain of $\sim 12 \mathrm{~km}$, found from spectral analysis of the topography shown in Fig. 1. However, the change in the background wind velocity with height likely leads to refraction of such gravity waves resulting in modifications of the horizontal structure. Nonetheless, we see comparable horizontal wavelength values not just over these two days, but on most days in February.

Third, on two of the February days studied (Fig. 2, days 57 and day 59), there appears to be a wave-like feature consisting of alternating vertical bands which are similar to the modeling results of ducted gravity waves which consist of alternating vertical bands with a periodicity of order $10 \mathrm{~min}$ (Snively and Pasko, 2003). Data from other days in February, even on consecutive days, did not demonstrate this pattern. The wave-like structure is seen in all of the zonal, meridional, and vertical wind profiles, on both days around 15:00 LT at $\sim 15 \mathrm{~km}$ altitude. On day 57 , the zonal variations are seen as westward wind excursion (lowest altitude) from an otherwise easterly wind profile, corresponding to a northward wind excursion in the meridional wind profile. On day 59, the zonal variations are seen in the eastward wind excursion (lowest altitude) from the otherwise easterly wind profile, corresponding to a southward wind excursion in the meridional wind profile.

In Figure 3 we show a close up of the wave-like features seen in the afternoon on day 57, without any filtering (i.e. raw data is shown). The observed wave-like feature in the westerly jet at $16 \mathrm{~km}$ altitude have an observed (residual) horizontal amplitude between $3-5 \mathrm{~m} \mathrm{~s}^{-1}$ and an observed period of $\sim 90 \mathrm{~min}$. No shorter periods were observed in the raw data. An estimate of the zonal (also, meridional and vertical winds, not shown) wind power spectral density (PSD) indicates that the feature is not monochromatic (despite a local peak in the PSD at approximately $72 \mathrm{~min}$ ) and instead resembles the PSD of a "square wave", indicating potential amplitude saturation or wave mode mixing. Any apparent propagation direction and speed could not be determined and this uncertainty must be taken into account towards our estimation of the observed period. These results are consistent with the analysis of day 59 , but at $14 \mathrm{~km}$ altitude.

To see if these observed stationary-wave induced winds have the potential to act as a Doppler duct for an impinging upward propagating monochromatic gravity wave, we plot altitude profiles of the gravity wave vertical wavenumbersquared $\left(\mathrm{m}^{2}\right)$ in Fig. 4 corresponding to a wave with the observed period of $90 \mathrm{~min}$ and with the winds seen on day 57 . This calculation used the Taylor-Goldstein equation which kept the background wind curvature and vertical shear terms (Simkhada et al., 2009). This approach is typically utilized to investigate ducting regions, as regions of positive $\left(\mathrm{m}^{2}\right)$ indicate vertical gravity wave propagation, while regions of negative $\left(\mathrm{m}^{2}\right)$ indicate wave evanescence and/or reflection. Due to a lack of information on the horizontal wavelength and propagation direction, we must assume (a) that the feature is propagating in the direction of the background wind, and (b) a range of horizontal wavelengths. As seen in Fig. 4, there are altitude regions where a high $\mathrm{m}^{2}$ is bounded above and below by values less than, or approaching, zero, like at $16 \mathrm{~km}$ and $18 \mathrm{~km}$ altitudes. Thus these wind jets certainly appear to be capable of sustaining Doppler-ducted features for a range of very short horizontal wavelengths. A similar analysis utilizing a set of waves propagating directly against the wind flow does not qualitatively change this result.

Fourth, on day 57, there even appears to be a traveling, upward propagating gravity wave (i.e., downward tilted phase 

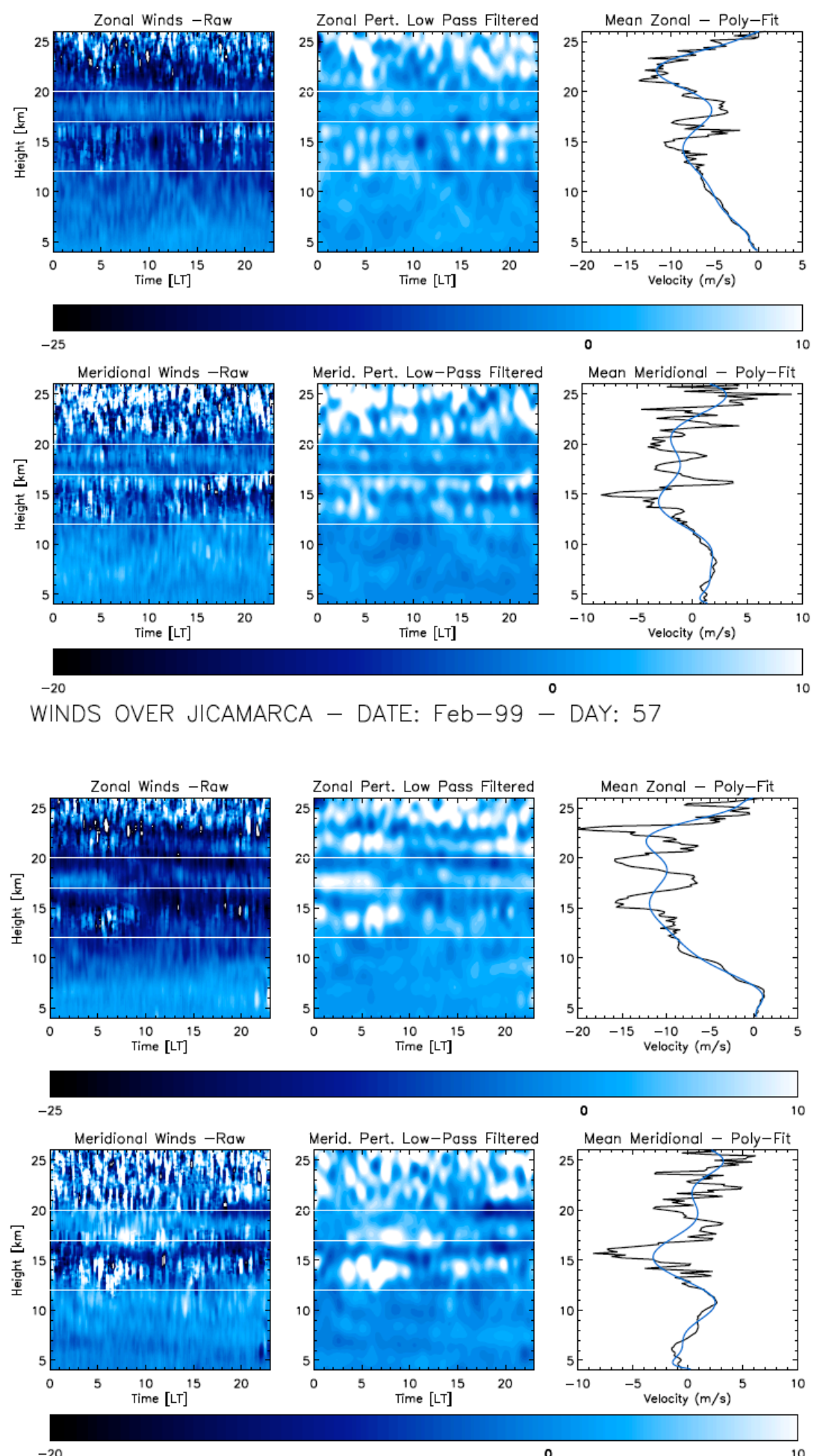

WINDS OVER JICAMARCA - DATE: Feb-99 - DAY: 59

Fig. 2. Contour plots showing MST winds measured over Jicamarca on two days in February 1999. The left column shows the raw zonal (upper row/panel) and meridional (lower row/panel) wind measurements, the right column shows the daily mean winds with a polynomial fit, and the center column shows the low-pass filtered perturbations from the estimated daily mean vertical wind profile. Note that the color scale for the zonal winds is not the same as the color scale for the meridional winds. Horizontal white bars represent bounding heights of high SNR (see text). 

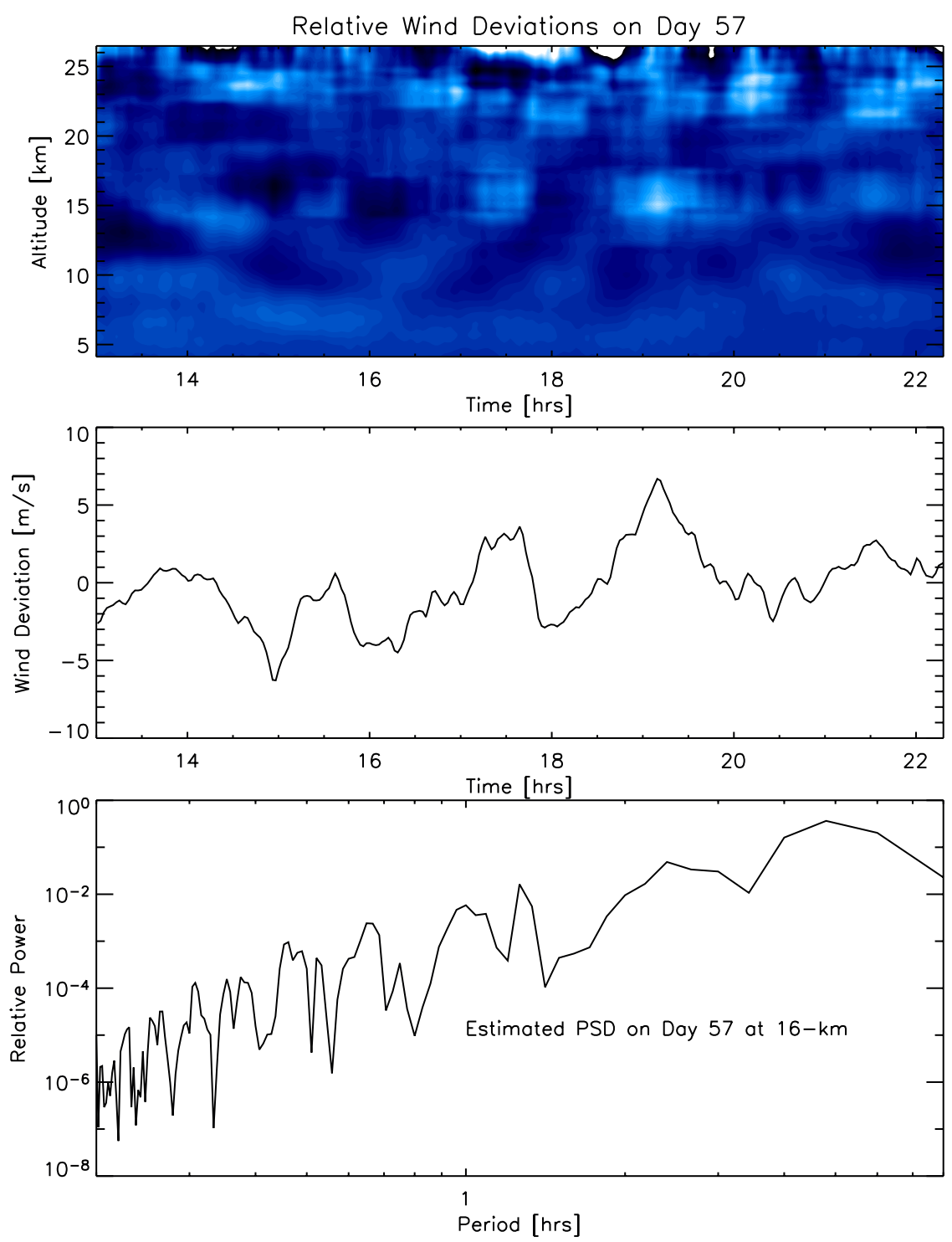

Fig. 3. More detailed view of the ducted feature from day 57. (top) Raw zonal wind deviations from the daily mean wind profile, ranging from $-5 \mathrm{~m} \mathrm{~s}^{-1}$ to $5 \mathrm{~m} \mathrm{~s}^{-1}$ on the black-blue-white color table. No filtering has been utilized. [middle] Wind deviation profile at $16 \mathrm{~km}$. (bottom) An estimate of the power spectral density [PSD] from the $16 \mathrm{~km}$ altitude.

line progression) occurring at approximately 11:00 LT and ending around 16:00 LT, with a vertical wavelength of $\sim 6 \mathrm{~km}$ and an observed period of $\sim 4 \mathrm{~h}$. No similar traveling wave signatures were seen on the other days.

\section{Analysis}

Given the information presented above, the initial conclusion was that we were observing the signature of a gravity wave being Doppler-ducted by wind shears associated with the phases of the stationary mountain gravity waves. However, the observation of a $90 \mathrm{~min}$ period, which is rather large for a ducted wave, and the spectral analysis presented in Fig. 3, which is indicative of a square wave amplitude envelope, are suggestive of a potentially different phenomenon. As such, in an effort to explore the ability of a monochromatic gravity wave to be ducted in such a wind structure and have such observed characteristics, we developed a time-stepped twodimensional (spatial x-horizontal and z-vertical domains) numerical model similar to that of Snively and Pasko (2003).

The model structure follows the framework for implementing high-resolution Godunov-type methods (LeVeque, 2003), and is implemented within the CLAWPACK software package (http://www.amath.washington.edu/ $\sim$ claw). The model is similar to the one by Ahmad and Lindeman (2007), which assumes that the atmosphere is 


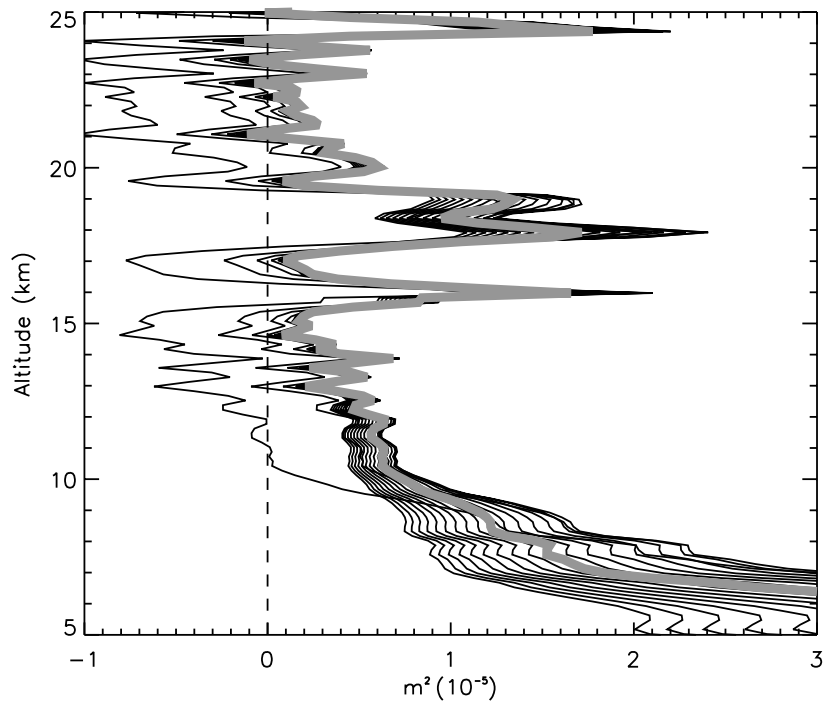

Fig. 4. Altitude profiles of the gravity wave vertical wavenumbersquared $\left(\mathrm{m}^{2}\right)$ for gravity waves with horizontal wavelengths ranging from $2 \mathrm{~km}$ to $20 \mathrm{~km}$ and with an observed period of $90 \mathrm{~min}$. The profile at a horizontal wavelength of $10 \mathrm{~km}$ is shown in grey. The dashed vertical line at $\mathrm{m}^{2}=0$ represents the boundary between freely propagating $\left(\mathrm{m}^{2}>0\right)$ and evanescent/reflected $\left(\mathrm{m}^{2}<0\right)$ regions.

represented by an ideal, dry, inviscid gas. The basic governing equations for atmospheric flows are given by conservation of mass, momentum, energy and equation of state, which can be simplified to the following 2-D Euler equations:

$\frac{\partial U}{\partial t}+\frac{\partial F}{\partial x}+\frac{\partial G}{\partial y}=Q$

with

$U=\left[\begin{array}{c}\rho \\ \rho u \\ \rho v \\ \rho \theta\end{array}\right] \quad F=\left[\begin{array}{c}\rho u \\ \rho u^{2}+p \\ \rho u v \\ \rho u \theta\end{array}\right]$
$G=\left[\begin{array}{c}\rho v \\ \rho u v \\ \rho v^{2}+p \\ \rho v \theta\end{array}\right] \quad Q=\left[\begin{array}{c}0 \\ 0 \\ -\rho g+F_{\mathrm{s}} \\ 0\end{array}\right]$

where $\rho$ is the atmosphere density, $u$ is the horizontal velocity along the $\mathrm{x}$-direction, $v$ is the vertical velocity along the z-direction, $p$ is the pressure, $\theta$ is the potential temperature, and $F$ is a forcing function in the vertical (Andrews et al., 1987). This set of equations is hyperbolic in nature and we adapt a Godunov-type scheme for hyperbolic conservation laws suggested by LeVeque (2003), employing flux-based wave decompositions proposed by Ahmad and Lindeman (2007) to solve the Riemann problems.

The uppermost height of domain simulation is chosen to be $220 \mathrm{~km}$ with a sponge layer spanning from $200 \mathrm{~km}$ to $220 \mathrm{~km}$. The sponge layer is thus at a much higher altitude than the altitude range being modeled; such a configuration was selected to maximally reduce gravity wave reflection from the top model layer and therefore ensure an open boundary condition for the simulation. The horizontal extent of the numerical domain is $1200 \mathrm{~km}$ with a $100 \mathrm{~km}$ thick sponge layer at both sides - again for open boundary considerations. The vertical and horizontal model resolutions are $0.25 \mathrm{~km}$ and $1 \mathrm{~km}$, respectively, and the nominal time-step is chosen to satisfy the Courant parameter. Model output was recorded every $5 \mathrm{~s}$.

The atmospheric background state parameters were specified at the beginning of the run and not allowed to vary in time. An isothermal background temperature was used in this simulation, with $T=300 \mathrm{~K}$ [and correctly converted to potential temperature, $\theta]$. Such a temperature background removes any potential for thermal ducting, thus allowing us to focus only on Doppler ducting. Furthermore, there is little vertical variation in the mean temperature profile in the upper troposphere/lower stratosphere at equatorial sites. For this simulation we have run the model with two different zonal wind profiles. The first was a windless run that serves as a control run. The second wind profile was also windless, except for Gaussian-shaped jet of maximum amplitude of $-15 \mathrm{~m} \mathrm{~s}^{-1}$, centroid altitude of $15 \mathrm{~km}, 1-\sigma$ RMS vertical width of $4 \mathrm{~km}$, and which filled the horizontal domain. We note that this $4 \mathrm{~km}$ RMS vertical width is approximately four times larger than that observed in wind profiles shown in Fig. 2 and will be further commented.

In order to spawn a potentially ducted wave, a source disturbance is used in the model that mimics the effects of a localized vertical oscillation with a characteristic horizontal wavelength, $\frac{2 \pi}{k_{\mathrm{x}}}$, and frequency, $\omega$ and amplitude modulated by a Gaussian envelope in space and time $\left(\sigma_{\mathrm{t}}, \sigma_{\mathrm{x}}, \sigma_{\mathrm{z}}\right.$, as RMS Gaussian values). The source took the form

$F_{\mathrm{S}}(x, z, t)=F_{0} \exp \left(-\frac{\left(x-x_{0}\right)^{2}}{2 \sigma_{\mathrm{x}}^{2}}-\frac{\left(z-z_{0}\right)^{2}}{2 \sigma_{\mathrm{z}}^{2}}-\frac{\left(t-t_{0}\right)^{2}}{2 \sigma_{\mathrm{t}}^{2}}\right)$
$\cos \left(k_{\mathrm{x}} x\right) \cos (\omega t)$

and was located at $x_{0}$ and $z_{0}$ of $450 \mathrm{~km}$ and $3 \mathrm{~km}$, respectively. The horizontal, vertical, and temporal scales of the disturbance were $10 \mathrm{~km}, 2 \mathrm{~km}$, and $5.86 \mathrm{~min}$ [approximately the Brunt-Vaisala frequency, assumed constant in the upper troposphere and lower stratosphere], respectively. The initial amplitude disturbance was equivalent to a $1.2 \mathrm{c} \mathrm{m} \mathrm{s}^{-1}$ vertical wind, and the horizontal wavelength and period were initially set to $20 \mathrm{~km}$ and $10 \mathrm{~min}$, respectively.

Results of the two model runs are shown in Fig. 5. For the control run (right column) we model an upwards propagating gravity that extends well into the upper atmosphere. There is no indication of any ducting structures. For the run with a westward, Gaussian-shaped jet centered at $15 \mathrm{~km}$ (left column), we clearly see ducted waves of $85.4 \%$ of the initial source at time $16000 \mathrm{~s}$, an observed horizontal wavelength of $\sim 20 \mathrm{~km}$, and propagation to the east with an observed speed 

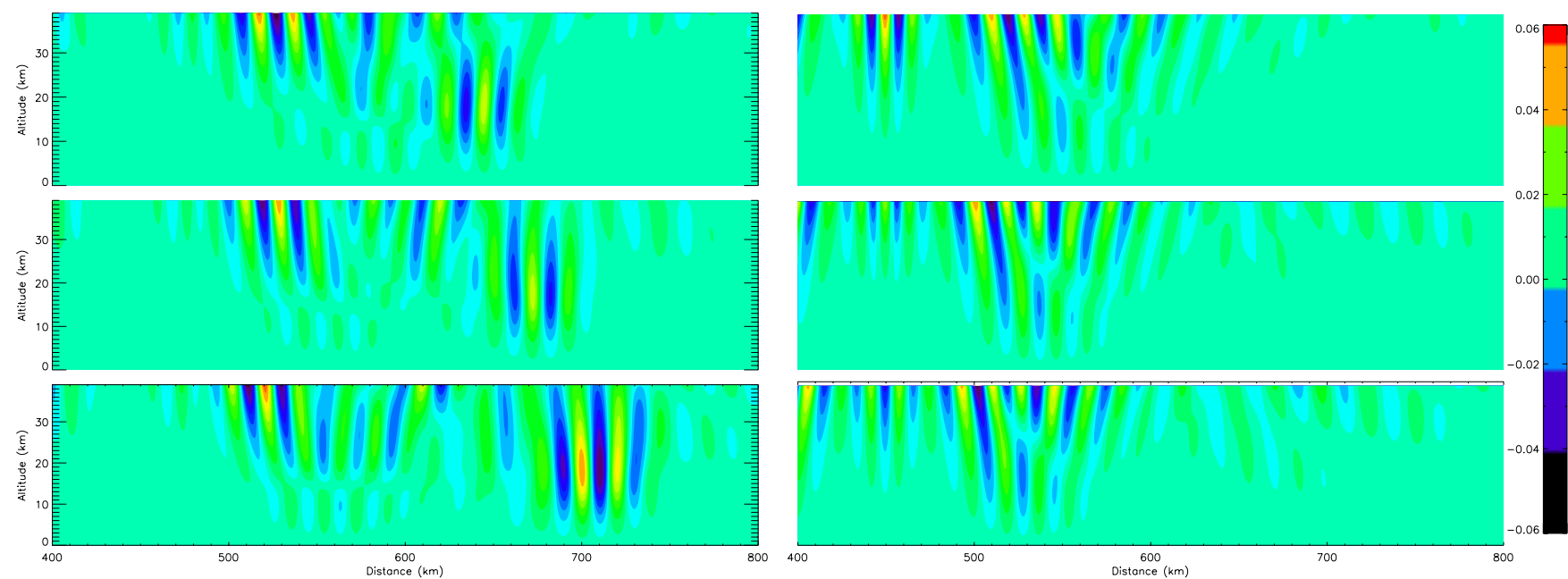

Fig. 5. Vertical velocity simulation results. The left column shows the results of the simulation with a Doppler duct located at $\sim 15 \mathrm{~km}$ for three progressively increasing time intervals of $12000 \mathrm{~s} / 3.33 \mathrm{~h}, 14000 \mathrm{~s} / 3.89 \mathrm{~h}$, and $16000 \mathrm{~s} / 4.44 \mathrm{~h}$. The right column shows the results from the simulation without a Doppler duct at the same time intervals. Color-bar units are in $\mathrm{m} \mathrm{s}^{-1}$.
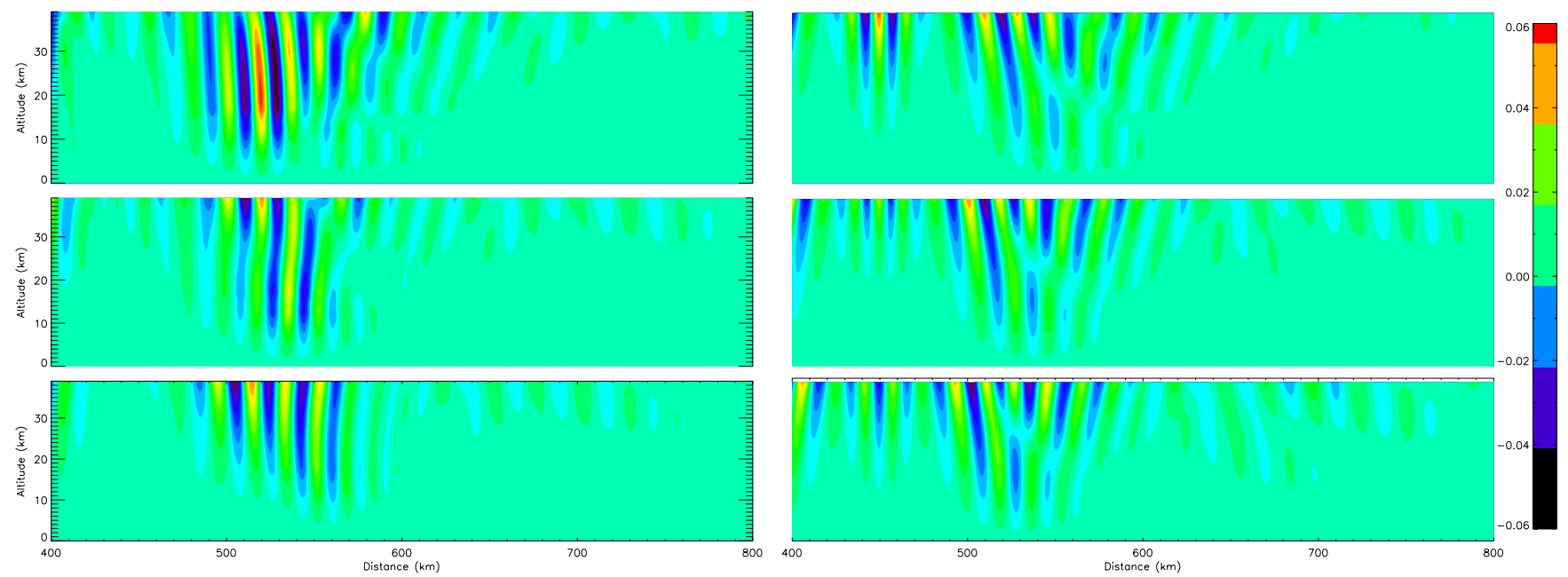

Fig. 6. Vertical velocity simulation results similar to Fig. 5, but with a $1 \mathrm{~km}$ RMS wind width. The left column shows the results of the simulation with a Doppler duct located at $\sim 15 \mathrm{~km}$ for three progressively increasing time intervals of $12000 \mathrm{~s} 3.33 \mathrm{~h}, 14000 \mathrm{~s} / 3.89 \mathrm{~h}$, and $16000 \mathrm{~s} / 4.44 \mathrm{~h}$. The right column shows the results from the simulation without a Doppler duct at the same time intervals. Color-bar units are in $\mathrm{ms}^{-1}$.

of $\sim 15 \mathrm{~m} \mathrm{~s}^{-1}$. We note that the peaks have an amplitude that is modulated by a broad Gaussian envelope, unlike the observations, which is imposed by the source term expression. A change of this source term expression can likewise modulate the sinusoidal peak amplitudes. Thus, when a rectangle envelope function was used in the source term the resultant ducted waves also had a rectangle amplitude profile (not shown). If observed from a fixed site, the simulated ducted structure would have a period of $\sim 22 \mathrm{~min}$ - approximately a fourth as much as the period of the ductal-feature observed over Jicamarca.
Given this observed period being four times too fast as compared to the observations, we undertook a number of modeling runs that used various configurations of the above parameters. Generally, we saw that changing the model wave source parameters (i.e., the horizontal wavenumber and period by factors of up to 3 ) did not dramatically alter the observed period of the ducted wave. However, changing the width of the wind jet did modify the ducted structure, with a narrower duct resulting in a slower progressing wave packet and thus a longer observed wave period. A wind jet with a RMS width of $1 \mathrm{~km}$, which is much more in line with the observations from Fig. 2 resulted in a ducted feature that had an 
observed period of 90 min as seen in Fig. 6. We are still investigating this nature of the duct width and the period that a sustained wave would have, as explored theoretically in Chimonas and Hines (1986).

\section{Discussion and conclusions}

Comparison of the model output with Jicamarca MST observations indicates that we are observing the signature of a Doppler-ducted gravity wave within the sinusoidal wind variations of the upper troposphere/lower stratosphere. However, while the model results do replicate the observations qualitatively, there are nonetheless important aspects of the observations that need to be resolved. First, through tuning the source term envelope function we were able to match the square-wave nature of the observations. However, the physical existence of such a source spectrum is questionable. What tropospheric system can instantaneously turn gravity waves on and off? Are we mimicking a sudden onset of convection? At this time we have no evidence supporting such a source existing at the time of these observations and questions arise as to whether the model results match the observations for the wrong reason.

The second issue deals with resolving the meteorology of the upper troposphere/lower stratosphere above Jicamarca. A better determination needs to be made as to whether the vertically-varying sinusoidal variations in the background wind are indeed due to stationary gravity waves, or longperiod Kelvin waves, or perhaps due to other meteorological features like convective rolls (Etling and Brown, 1993). Given the topology of the terrain surrounding Jicamarca, we have assumed that it was a stationary gravity wave but further studies and reverse gravity wave ray-tracing are needed to confirm this.

The third issue deals with identifying the source of the observed Doppler-ducted gravity waves. Data from day 57 indicate a traveling gravity wave may have "seeded" the duct, but no such traveling gravity wave signature was present on day 59. Furthermore, seeing that the ducted structure was observed at approximately the same time of day for both observations presented here, there may be a diurnal heating mechanism responsible for the ducted wave "seeding."

The fourth and most important issue deals with the broader question of whether or not a Doppler-ducted feature was really observed. That is, the spatially confined periodicities could well be the result of a more complex phenomena, like wave breaking due to dynamical instabilities. This issue is beyond the scope of this work at this time but certainly needs to be considered, especially considering that this initial study involved the use of a limited data sample from the larger MST data set. Further studies are required to study this extensive dataset and better characterize the occurrences of these features.
Should these three issues be satisfactorily resolved, the upper troposphere/lower stratosphere environment above a location such as Jicamarca would be an ideal natural laboratory to study Doppler ducting phenomena, including gravity wave ducting and potential "bore" formation in Doppler ducts. The steady winds provide excellent dynamical ducts for extended periods of time and the equatorial location likely provides a plethora of convective gravity wave sources. Furthermore, the excellent signal-to-noise ratio from the Jicamarca MST system, combined with radiosonde data and meteorological diagnostics, would allow for a detailed study of the physics of ducting, including duct-coupling and "kissing modes." These unique factors should motivate further modeling efforts and observations.

Acknowledgements. The authors would like to thank Ronald Woodman (Instituto Geofisico del Peru) for this data set and for his constructive comments. We also thank the personnel of the Radio Observatorio de Jicamarca for their assistance in collecting and preparing this data set. We very much appreciate the helpful and supportive comments of the reviewers of this paper. This work was supported by grants from the National Science Foundation [NSF-ATM-0735452 and NSF-ATM-0457277].

Edited by: F.-J. Lübken

\section{References}

Ahmad, N. and Lindeman, J.: Euler solutions using flux-based wave decomposition, Int. J. Num. Meth. Fluids, 54, 47-72, 2007.

Andrews, D. G., Holton, J. R., and Leovy, C. B.: Middle Atmosphere Dynamics, Academic Press, 113-219, 1987.

Brown, L. B., Gerrard, A. J., Meriwether, J. W., and. Makela, J. $\mathrm{J}$ : All-sky imaging observations of mesospheric fronts in OI $557.7 \mathrm{~nm}$ and broadband $\mathrm{OH}$ airglow emissions: Analysis of frontal structure, atmospheric background conditions, and potential sourcing mechanisms, J. Geophys. Res., 109, D19104, doi:10.1029/2003JD004223, 2004.

Chimonas, G. and Hines, C. O.: Doppler Ducting of Atmospheric Gravity Waves, J. Geophys. Res., 91, 1219-1230, 1986.

Dewan, E. M. and Picard, R. H.: Mesospheric bores, J. Geophys. Res., 103, 6295-6306, 1998.

Dewan, E. M. and Picard, R. H.: On the origin of mesospheric bores, J. Geophys. Res., 106, C2927, doi:10.1029/2000JD900697, 2001.

Etling, D. and Brown, R. A.: Roll Vortices in the Planetary Boundary Layer: A Review, Boundary Layer Meteorology, 65, 215248, 1993.

Fechine, J., Wrasse, C. M., Takahashi, H., Medeiros, A. F., Batista, P. P., Clemesha, B. R., Lima, L. M., Fritts, D., Laughman, B., Taylor, M. J., Pautet, P. D., Mlynczak, M. G., and Russell, J. M.: First observation of an undular mesospheric bore in a Doppler duct, Ann. Geophys., 27, 1399-1406, doi:10.5194/angeo-271399-2009, 2009.

LeVeque, R. J.: Clawpack Version 4.2 User's Guide, Technical Report, University of Washington, http://depts.washington.edu/ clawpack/clawpack-4.3/doc/claw42/clawuser.pdf, 2003. 
Meriwether, J. W. and A. J. Gerrard: Mesosphere inversion layers and stratosphere temperature enhancements, Rev. Geophys., 42, RG3003, doi:10.1029/2003RG000133, 2004.

Riggin, D. M., Kudeki, E., Feng, Z., Sarango, M. F., and Lieberman, R. S.: Jicamarca radar observations of the diurnal and semidiurnal tide in the troposphere and lower stratosphere, J. Geophys. Res., 4062, doi:10.129/2001JD001216, 2002.

Riggin, D. M., Kudeki, E., and Sarango, M.: Tropospheric and stratospheric momentum flux measurements from radar wind data collected at Jicamarca, J. Atmos. Solar-Terr. Phys., 66, 277283, 2004.

She, C. Y., Li, T., Williams, B. P., Yuan, T., and Picard, R. H.: Concurrent $\mathrm{OH}$ imager and sodium temperature/wind lidar observation of a mesopause region undular bore event over Fort Collins/Platteville, Colorado, J. Geophys. Res., 109, 2210722115, 2004.

Simkhada, D. B., Snively, J. B., Taylor, M. J., and Franke, S. J.: Analysis and modeling of ducted and evanescent gravity waves observed in the Hawaiian airglow, Ann. Geophys., 27, 32133224, doi:10.5194/angeo-27-3213-2009, 2009.
Snively, J. B. and Pasko, V. P.: Breaking of thunderstormgenerated gravity waves as a source of short-period ducted waves at mesopause altitudes, Geophys. Res. Lett., 30, 2254, doi:10.1029/2003GL018436, 2003.

Snively, J. B., Pasko, V. P., Taylor, M. J., and Hocking, W. K.: Doppler ducting of short period gravity waves by midlatitude tidal wind structure, J. Geophys. Res., 112, A03304, doi:10.1029/2006JA011895, 2007.

Snively, J. B. and Pasko, V. P.: Excitation of Mesospheric Gravity Waves by Tropospheric Sources, J. Geophys. Res., 113, A06303, doi:10.1029/2007JA012693, 2008.

Smith, S. M., Taylor, M. J., Swenson, G. R., She, C. Y., Hocking, W., Baumgardner, J., and Mendillo, M.: A multidiagnostic investigation of the mesospheric bore phenomenon, J. Geophys. Res., 108, 1083-1101, 2003.

Taylor, M. J., Turnbull, D. N., and Lowe, R. P.: Spectrometric and imaging measurements of a spectacular gravity wave event observed during the ALOHA-93 campaign, Geophys. Res. Lett. 20, 2849-2852, 1995. 